Fourth International Conference on Sustainable Construction Materials and Technologies http://www.claisse.info/Proceedings.htm

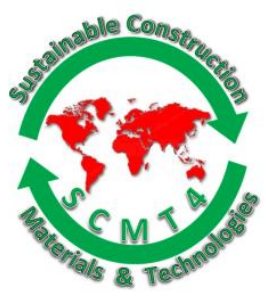

SCMT4

Las Vegas, USA, August 7-11, 2016

\title{
Use-Stage Environmental Performances of Cementious-Woodchip Compound Products Considering Resilience Measures in Disaster Situation
}

\author{
Masaki Tamura ${ }^{1 a}$, and Yumi Ohiwa ${ }^{1 b}$ \\ ${ }^{1}$ Department of Architecture, School of Architecture, Kogakuin University, P. O. Box 163-8677, \\ 1-24-2 Nishi-shinjyuku, Shinjyuku-ku, Tokyo, JAPAN. \\ ${ }^{1 a}$ Email: <masaki-t@cc.kogakuin.ac.jp>, ${ }^{1 b}$ Email: 〈ohiwa.ym@gmail.com>
}

\begin{abstract}
Today's urbanized areas in Japan, a lot of concrete structures have been built. On the other hand, the performance conditions in a part of them have been deteriorating gradually, and the various harmful effects of natural disasters such as big earthquake and global warming phenomenon in urban and regional areas would be necessary to be mitigated immediately. The various effective resilience measures would be important to be carried out toward the near future.

Overview these conditions, the new concrete production methods and systems to be considered the environmental effects and resilience performances would be indispensable to be introduced in Japan. This study focused on the development of Cementious wood-chips Compound Products (CCP). The original wood-chips materials of CCP were using disaster waste wood materials released by the Great East Japan Earthquake 2011.
\end{abstract}

In the experiments, we prepared many types of CCP specimens to be applied for structural body and wall masonry unit, and evaluated the relationship between mix proportions of wood-chips and the fundamental properties. These mix proportions are different from content rates of water, particle size and volume of wood-chips and curing conditions, and we conducted these experimental evaluations in detail to the focus on use-stage environmental effects such as deterioration of surface texture in a outer exposure condition a and thermal radiated effects after evaluating a fundamental properties supposing to be applied for structural body.

As these results, it has been found that these use-stage environmental performances were related between the particle size of woodchip and volume mainly, and finally, It would be expected to increse the potential performance in use-stage of CCP by developing fundamental properties to be optimized the ratio of woodchip compositions.

\section{INTRODUCTION}

The Great East Japan Earthquake has happened at Tohoku area in Japan at 2011. At the site, a problem about a processing method of the rubbles of concrete or wood included in huge quantities of disaster waste was taken up intensely. After that, In a disaster area in Tohoku area, disaster rubble was utilized aggressively 
for construction of a breakwater and seawall and land filling, and finally, environment impact by disposing the disaster waste and rubble was seemed to be reduced largely. With the results of happening The Great East Japan Earthquake at 2011, over 20 million tons of disaster rubble was broken out at the moment, and over 11 million tons of Tsunami rubble was broken out along the sea shore area. Finally, it took the date of total disposal treatment more than 4 years.

On the other hands, at the time of Hanshin-Awaji Great Earthquake at 1995, over 15 million tons of disaster rubble was broken out at the moment, and these huge amount of rubble were applied as landfill of solid waste in a waterfront area or final disposal site. It cost 320 billion Japanese yen during the whole of construction, and the whole date of total construction more than 3 years was needed.

It is now, a Great Earthquake Under Tokyo Area will be predicted to occur in the near future. These are lots of old concrete building and old wooden residences in Tokyo. Therefore, when these buildings broke, it is said that the enormous amount of concrete and waste rubble would occur to some extend not to be compared with The Hanshin-Awaji Great Earthquake at 1995 and The Great East Japan Earthquake at 2011.Moreover, some reports are noticed that 96 million tones of enormous disaster rubble will break out by occurrence a Great Earthquake Under Tokyo Area, and it's assumed that 6.4 times of enormous damage quantity against Great Hanshin-Awaji Earthquake will happen. We would have a responsibility and an important task to excuse important role to decrease the huge amount of disaster rubble as a some types of recycled resource toward the future.

This study focused on the development of Cementious wood-chips Compound Products (CCP). In the experiment, the original wood-chips materials of CCP were using disaster waste wood materials released by the Great East Japan Earthquake 2011 (Figure 1).

We prepared many types of CCP specimens applied for structural body and wall masonry unit and evaluated the use-stage environmental performances such as deterioration of surface texture in a outer exposure condition a and thermal radiation effects after evaluating a fundamental properties supposing to be applied for structural body.

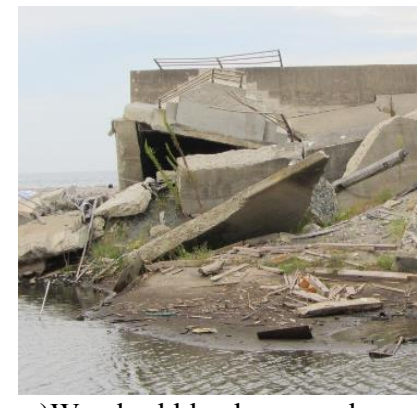

a)Wood rubble along seashore

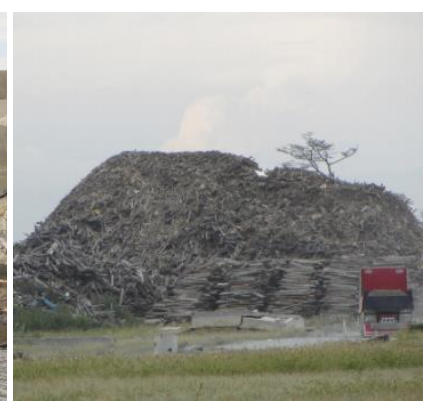

b)accumulated wood rubbles

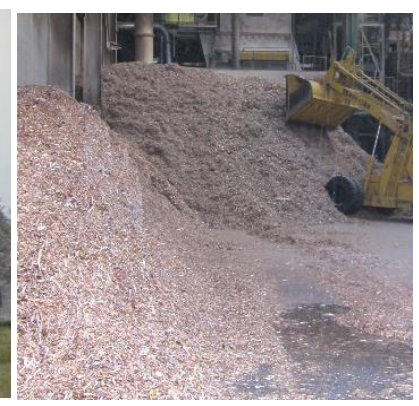

c)Recycling factory in Tokyo

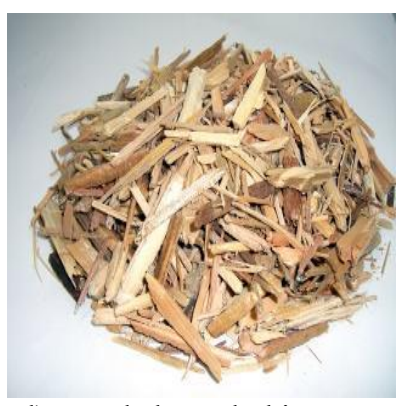

d)Recycled wood-chips

Figure 1. Disaster Scene of Great East Japan Earthquake and Resilience procedure (2011 2012)

\section{DEVELOPMENT OF CEMENTIOUS-WOODCHIP COMPOUNDPRODUCT(CCP)}

Materials of Experiments. Used materials of experiment is indicated in table 1. There were 8 kinds of panel type specimens as wood-chipsmasonry panel unit(M),cementious wood-chips compound products panel (CCP),concrete panel(CON) and wood panel(WS). 
Various wood-chips were introduced to produce CCP in the experiment. A small chips of larch tree (KS: particle size under $3 \mathrm{~mm}$ ) and a small chips of Japanese red pine tree(AS: particle size under $3 \mathrm{~mm}$ ) have been used in a market so as to produce a woody board for using general foundation board of residences at present. KS and AS are the comparative series against Recycled disaster wood-chips materials. The 3 kinds of Recycled disaster wood-chips were generated by using waste rubble of Eastern Japan Great Earthquake at 2011, and these were transported to the close area from Tohoku region and produced at a recycling wood factory in Tokyo area. The average size of recycled disaster wood-chips particle were divided into 3 levels among as small(RS: particle size under $3 \mathrm{~mm}$ ), middle(RM: particle size under 12mm)and Large(RL: particle size under 40mm).

Table 1. Materials of Experiments

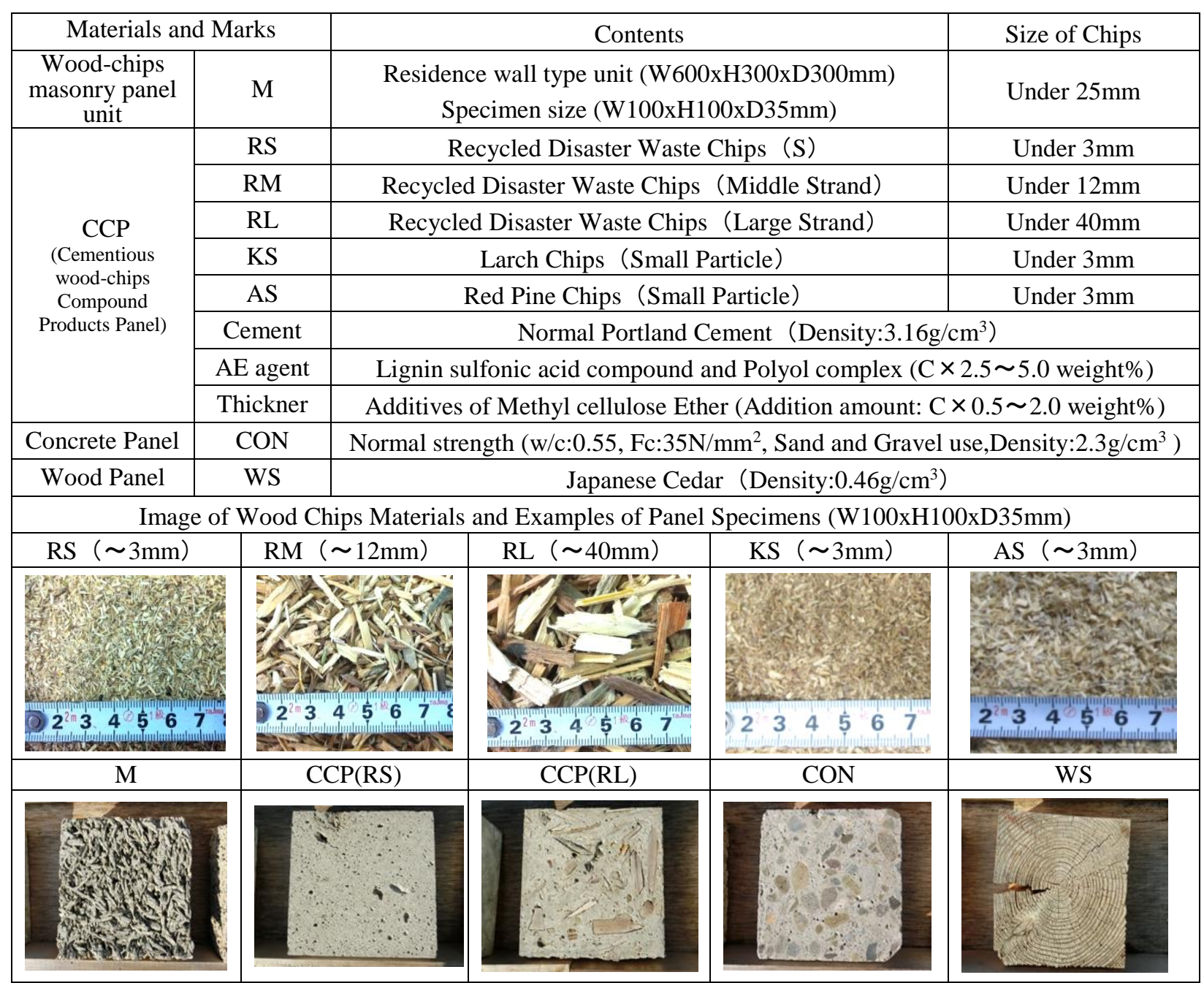

Experiment Factors and Levels. Experimental factors and levels are indicated in table 2, and the experimental items and methods are indicated in table 3.

There is wood-chips masonry unit used as a product actually in the foreign area which does not occur an earthquake in main. The basic physical properties of this masonry unit were investigated a bulk density, a particle size distribution and compressive strength beforehand to research the properties of Cementious wood-chips Compound Products (CCP).CCP was produced by 3 levels of W/C, 5 kinds of chips and 3 
levels of $\mathrm{P}$ (wood-chips)/C(cement) ratio. Fundamental properties of $\mathrm{CCP}$ is investigated by density and void volume in a specimens. Finally, the compressive test conditions of CCP was controlled by changing environment conditions of normal type(N),wet type(W) and dry type(D) among 24 hours after curing 4 weeks packing-aired conditions.

Table 2. Experiment Factors and Levels

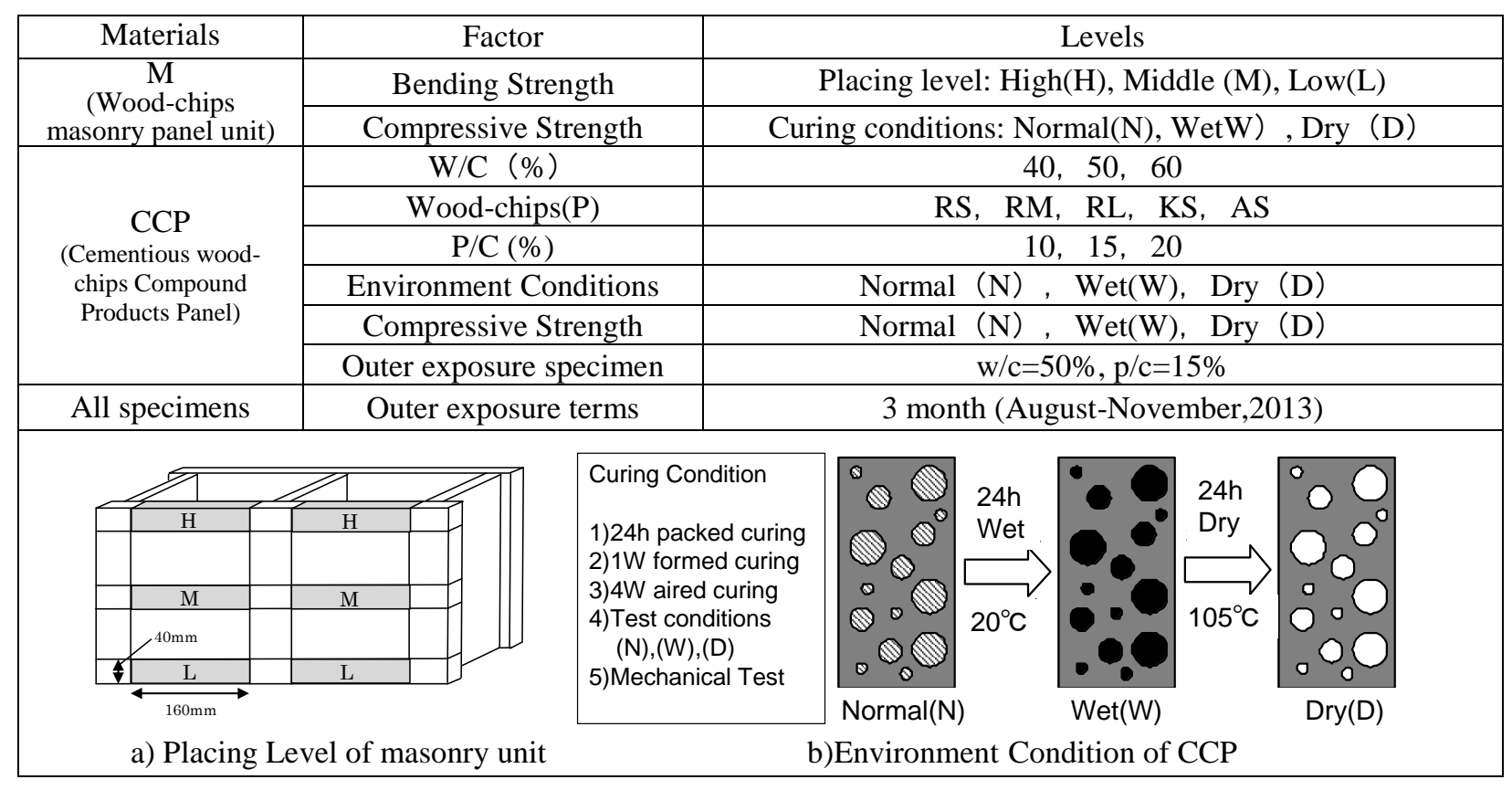

Table 3. Test Items and Methods

\begin{tabular}{|c|c|c|}
\hline Materials & Items & Methods and Contents \\
\hline \multirow{4}{*}{$\begin{array}{c}\text { M } \\
\text { (Wood-chips } \\
\text { masonry panel unit) }\end{array}$} & Bulk Density & Measure a weight of Wood-chip bar $(40 \times 40 \times 160 \mathrm{~mm})$ \\
\hline & Compressive Strength $(\mathrm{Fc})$ & JIS A $1108,(\phi 150 \times 300 \mathrm{~mm})$ \\
\hline & Bending Strength & JIS R 5201, $(40 \times 40 \times 160 \mathrm{~mm})$ \\
\hline & Void Volume & Referenced void volume of porous concrete $(40 \times 40 \times 70 \mathrm{~mm})$ \\
\hline \multirow{3}{*}{$\begin{array}{c}\text { CCP } \\
\text { (Cementious wood- } \\
\text { chips Compound } \\
\text { Products Panel) }\end{array}$} & Density & Environment conditions $(\mathrm{N}),(\mathrm{W}),(\mathrm{D})(\phi 100 \times 200 \mathrm{~mm})$ \\
\hline & Void Volume & Referenced void volume of porous concrete $(\phi 50 \times 100 \mathrm{~mm})$ \\
\hline & $\begin{array}{l}\text { Compressive Strength } \\
\text { Elastic Modulus }\end{array}$ & $\begin{array}{l}\text { JIS A } 1108, \text { JIS A } 1149(\phi 100 \times 200 \mathrm{~mm}) \\
\text { By changing Environment conditions(N),(W),(D) }\end{array}$ \\
\hline \multirow{3}{*}{ All series } & Outer exposure test & 3 months exposure in Hachioji,Tokyo (Aug.-Nov.,2013) \\
\hline & Color properties & $\begin{array}{l}\text { JIS Z } 8729 \text {, Color Value, L*(britness), a*(Red-Green color } \\
\text { phase), } b^{*} \text { (yellow-blue color phase), } \mathrm{C} * \mathrm{ab} \text { (color difference) }\end{array}$ \\
\hline & Termal radiated test & $\begin{array}{l}\text { Radiated 60minutes in a row by infrared ray lamp,and } 2 \text { times } \\
\text { of water wetting during the setting time }\end{array}$ \\
\hline
\end{tabular}

Production of Cementious Wood-chips Compound Products Panel(CCP). Mixture proportion of Cementious wood-chips Compound Products (CCP) is indicated in table 4.

Wood-chips masonry unit have used as building wall products actually for many years in foreign countries which does not occur earthquake issue. The fundamental properties of this masonry unit were controlled by product makers and the specifications. These product types are many varieties from the standpoint of size, thickness, strength, inserting thermal insulating material and so on. The masonry unit of the study is one of 
the typical types and the weight of masonry unit is light, and so the compressive strength is set almost 2-4 $\mathrm{N} / \mathrm{mm}^{2}$.

CCP was produced by 3 levels of W/C ratio(40\%,50\%,60\%), 5 kinds of wood-chips and 3 levels of P/C ratio(10\%,20\%,30\%). Fresh concrete conditions of CCP was controlled by using unitary quantities of admixture and methyl cellulose ether. Finally, the compressive test conditions of CCP was controlled by normal type(N), wet type(W) and dry type(D) among 24 hours curing after 4 weeks packing-aired curing conditions.

Table 4. Mixture Proportion of Wood-based Concrete (Unit:kg/m³)

\begin{tabular}{|c|c|c|c|c|c|c|c|}
\hline Mark & $\mathrm{W} / \mathrm{C}(\%)$ & $\mathrm{P} / \mathrm{C}(\%)$ & Cement(C) & Water(W) & Wood Particle $(\mathrm{P})$ & AE agent & Thickner \\
\hline$* 40$ & 40 & 10 & 1274 & 510 & 127 & \multirow{3}{*}{$\begin{array}{c}\mathrm{C} \times \\
0.25 \%\end{array}$} & \multirow{3}{*}{$\begin{array}{l}\mathrm{W} \times \\
0.1 \%\end{array}$} \\
\hline$* \mathbf{5 0}$ & 50 & 15 & 1146 & 573 & 172 & & \\
\hline$* 60$ & 60 & 20 & 1019 & 611 & 204 & & \\
\hline
\end{tabular}

Note) The Mark * is normal $(N)$,wet $(W)$ and dry type $(D)$ and $N 50$ was applied in the use-stage experiments.

\section{RESULTS AND DISCUSSIONS}

Fundamental Properties of Wood-chips Masonry Unit. Fundamental Properties of Wood-chips masonry unit is indicated in figure 2. As for a) relationship between bulk density and void volume, the lower placing concrete in the masonry unit from $\mathrm{H}$ to $\mathrm{L}$, the bulk density tends to increase proportionally and void volume decreases.

As for b) relationship between density and weight loss, these parameter on Drying series after getting wet was almost equal to Normal series. The water effects from taking rain would be small in the experiment. Although as to be seen c) relationship between curing methods and mechanical properties, compressive strength and elastic modulus of Drying series after getting wet was almost equal to wet series. The water effects from taking rain would be harmful. As for d) relationship between height levels of specimen and bending strength, the lower placing concrete in masonry unit, the higher bending strength because of increasing density of specimens.

Fundamental Properties of Cementious Wood-chips Compound Products (CCP). Fundamental Properties of CCP is indicated in figure 3. As for a) relationship between some particles and void volume, the bigger the particle size from RS to RL, the void volume tends to increase proportionally. In addition to the result, as for c) relationship between some particles and drying density, the bigger the particle size from RS to RL, the drying density tends to increase proportionally, and the absorption tends to decrease inversely. Although the RS series would be utilized as a raw material of CCP so that these performances of $\mathrm{RS}$ are almost equal to the CCP using AS and KS.

As for b) relationship between compressive strength and elastic modulus, The compressive strength of CCP was largely strengthened to $5-30 \mathrm{~N} / \mathrm{mm}^{2}$ and the Elastic modulus of CCP was same tendency to be compared the wood-chips masonry unit. As already mentioned forward, the wood-chips masonry unit has a problem regarding mechanical properties mainly, so it is important to be improved these properties by producing $\mathrm{CCP}$, and the mechanical property of CCP could be estimated by the structural design code of AIJ(Architectural Institute of Japan), such as illustrated under curve line of Autoclaved lightweight concrete $\left(\gamma=0.5 \mathrm{~g} / \mathrm{cm}^{3}\right)$. 


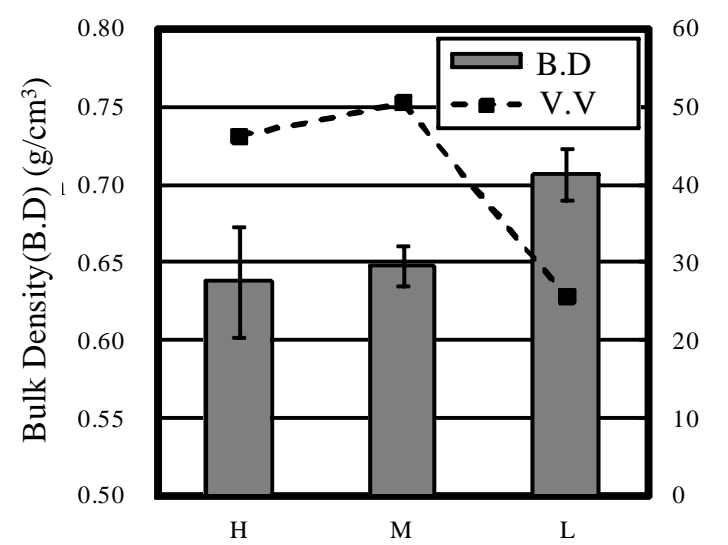

a)Bulk Density(B.D) and Void Volume(V.V)

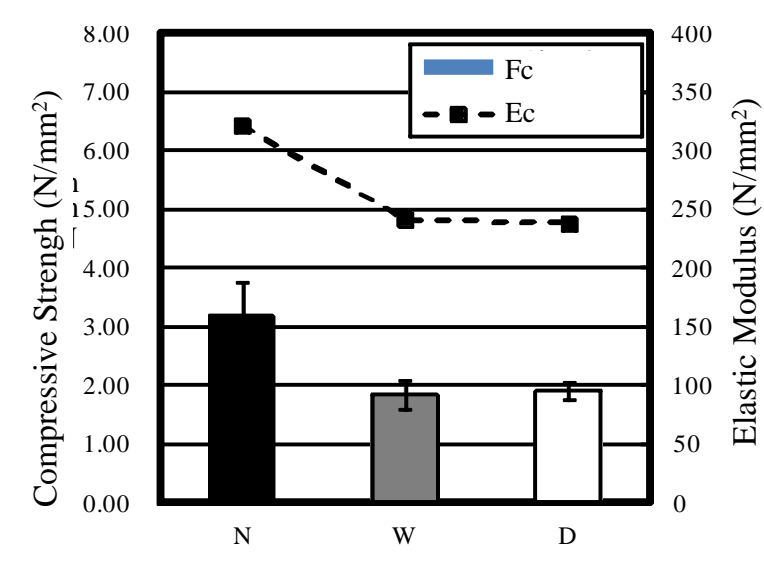

c) Compressive Strengh and Elastic Modulus

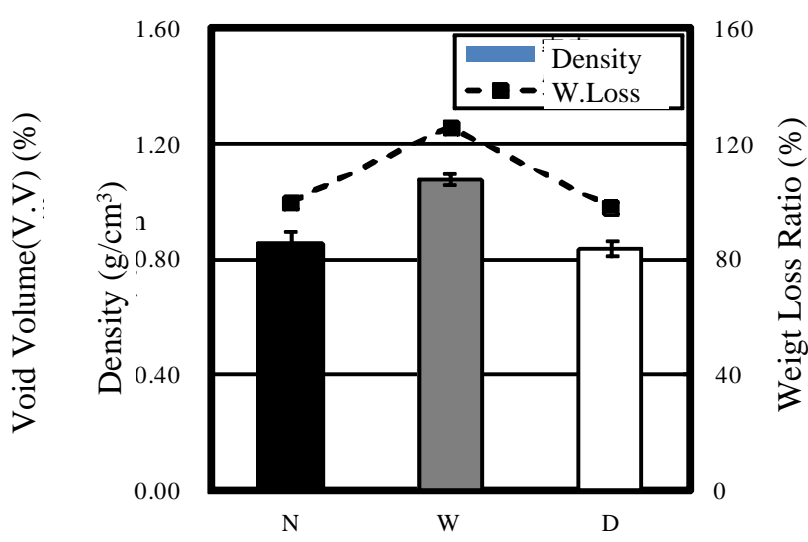

b)Density and Weight Loss Ratio

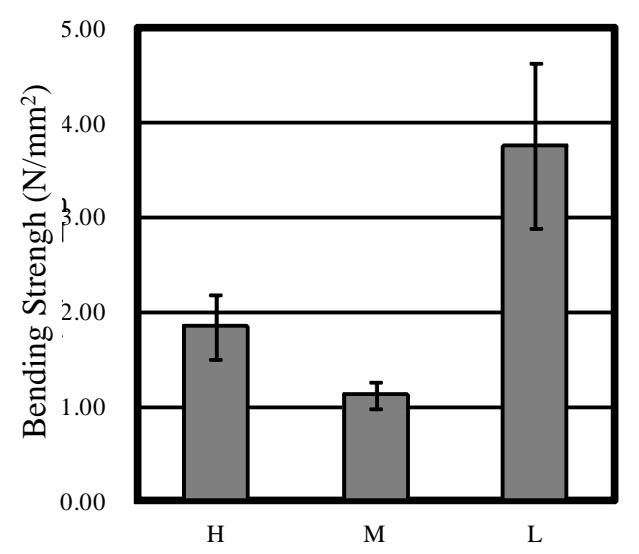

d) Bending and Height Levels of specimen

Figure 2. Fundamental Properties of Wood-chips masonry unit

\section{Effects of Wet and Dry conditions of Cementious Wood-chips Compound Products (CCP)}

The Effects of Wet(W) and Dry(D) conditions of CCP are indicated in figure 4. In general, Free water included in materials would be tendency to decrease several performances such as strength, deformation ability, durability and so on. The wood-chips of CCP may be also same, so the effects toward a)Density and Weight Loss Ratio and b)Compressive Strength and Elastic Modulus were observed.

As for the density and weight Loss Ratio in figure a), the density of Wet(W) series was naturally increasing than that of Normal(N)series, and after drying arrangement, it was decreasing to large extend than that of Normal(N)series. Particularly, These harmful effects against properties of CCP were seemed to be remarkable at using recycled disaster wood-chips rubble as RL.As for the compressive strength and elastic modulus in figure $b$ ), the compressive strength of Wet(W) series was almost decreasing than that of $\operatorname{Normal}(\mathrm{N})$ series, and after drying adjustment, though the strength did not recover to the extend that of $\operatorname{Normal}(\mathrm{N})$ series. In additions, the tendency of performance decreasing of $\mathrm{CCP}$ was seemed to be remarkable at elastic modulus. 


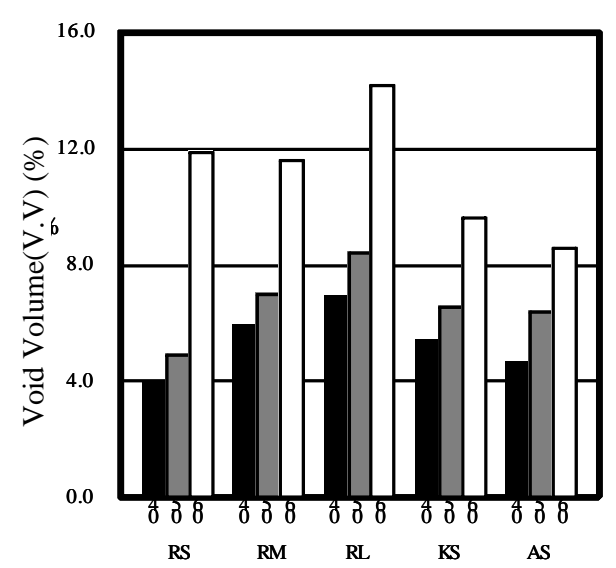

a)Void Volume of Wood-tip Concrete

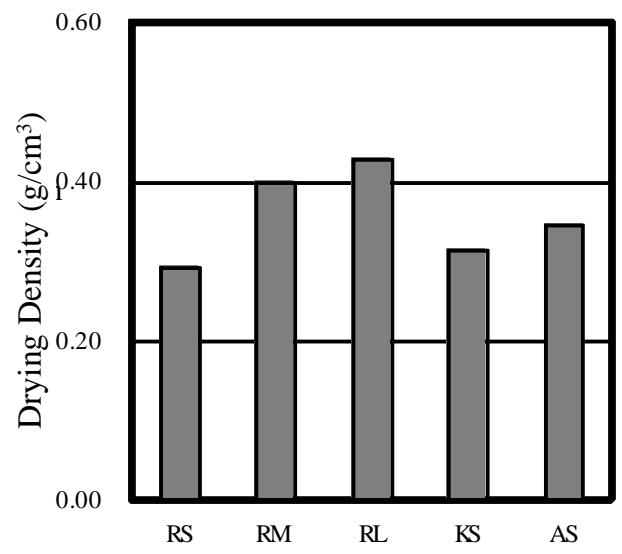

c)Dying density of Wood-tip aggregate

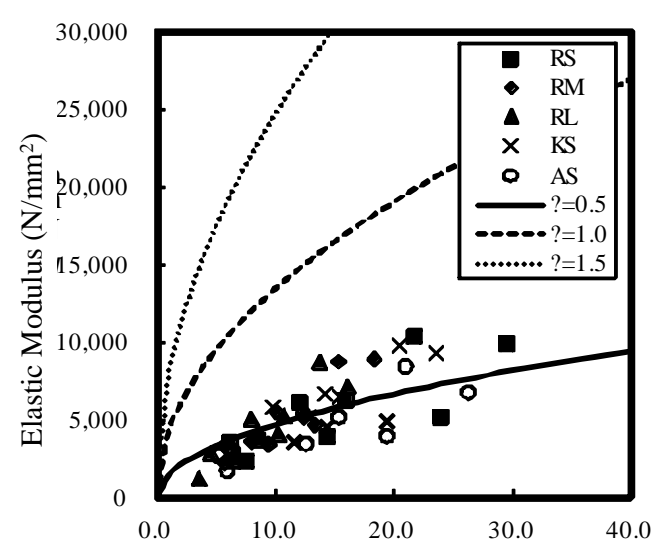

b) Compressive Strengh and Elastic Modulus

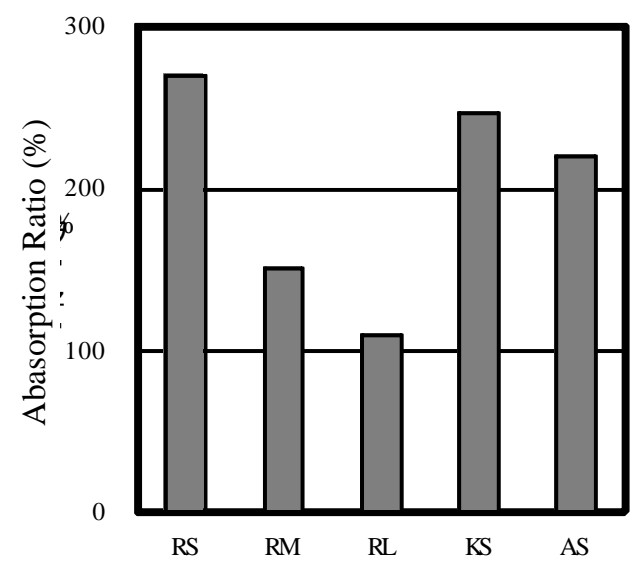

d)Absorption of Wood-tip aggregate

Figure 3. Fundamental Properties of CCP

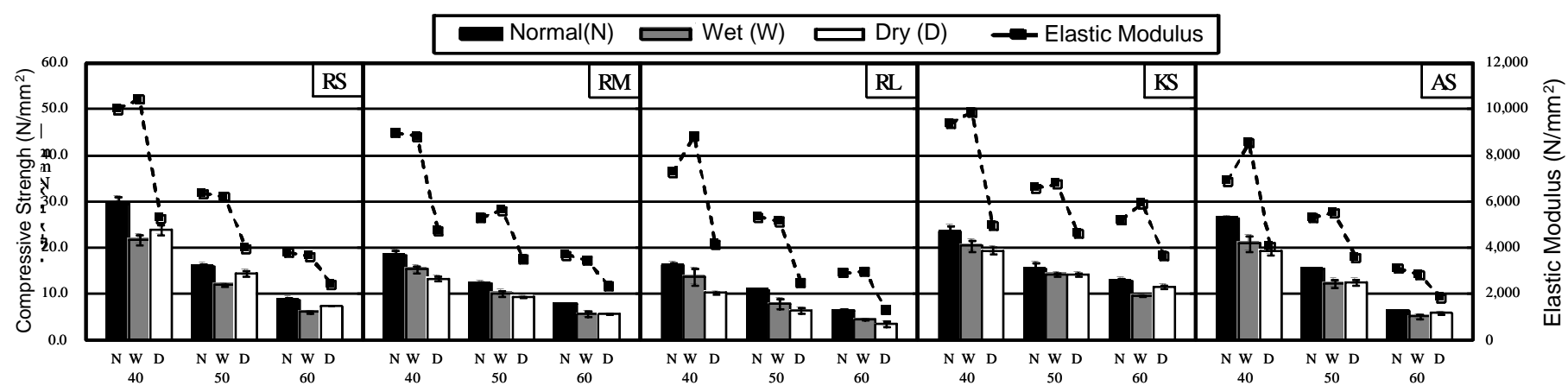

Figure 4. Compressive Strength and Elastic ModulusThe Effects of Wetting and Drying of CCP

\section{Use-stage Environmental Effects on Deterioration of Surface Texture of Cementious wood-chips}

Compound Products (CCP) in a Outer Exposure Condition .The results of deterioration on surface texture of CCP in a outer exposure condition is indicated in figure 5. The total 24 panels with 8 kinds of specimens $\mathrm{M}, \mathrm{RS}, \mathrm{RM}, \mathrm{RL}, \mathrm{KS}, \mathrm{AS}, \mathrm{CON}$ and WS had been exposed at a roof terrace of the building at Hachioji area in Tokyo for over three months at summer season 2013. These specimens were placed on the sloped board for 
south direction as shown at figure a)and $\mathrm{b}$ ) and evaluated the color properties on $\mathrm{L}^{*}($ brightness $), \mathrm{a}^{*}($ RedGreen color phase), $b^{*}\left(\right.$ yellow-blue color phase)and $\mathrm{C}^{*} \mathrm{ab}$ (color difference) as shown at figure c) and equation 1 and 2 .

$\mathrm{C}^{*} \mathrm{ab}=\left[\left(\mathrm{a}^{*}\right)^{2}+\left(\mathrm{a}^{*}\right)^{2}\right] 1 / 2$

$\triangle \mathrm{C}^{*} \mathrm{ab}=\mathrm{C}^{*} \mathrm{ab}$ (end)- $\mathrm{C}^{*} \mathrm{ab}$ (start)

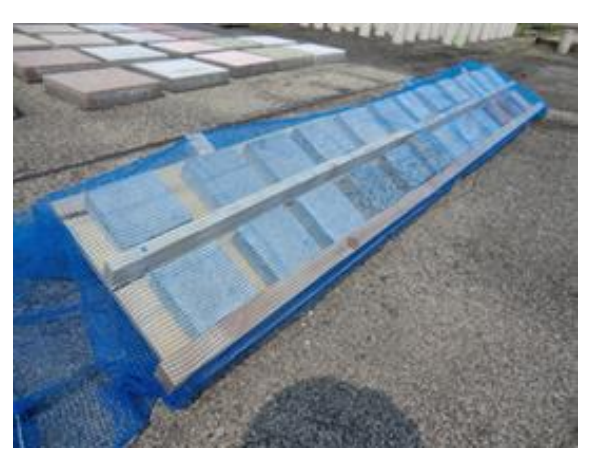

a)Outer Exposure Test

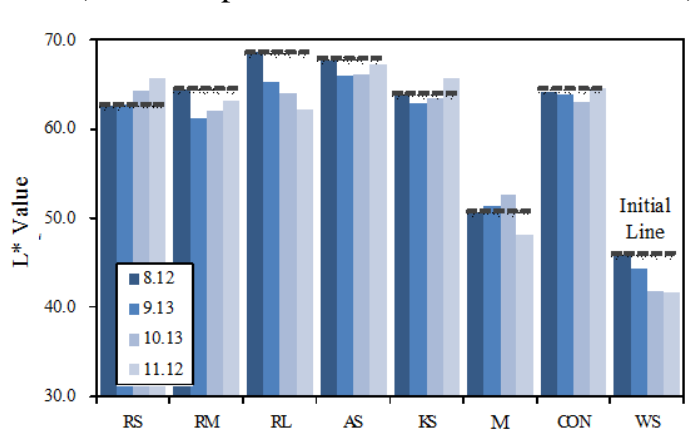

d)Time Changing of $L^{*}$ Value

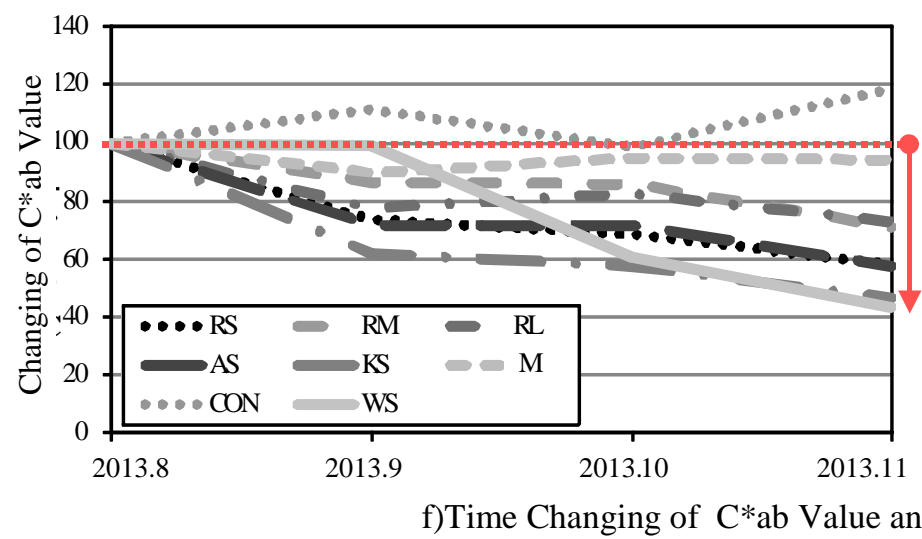

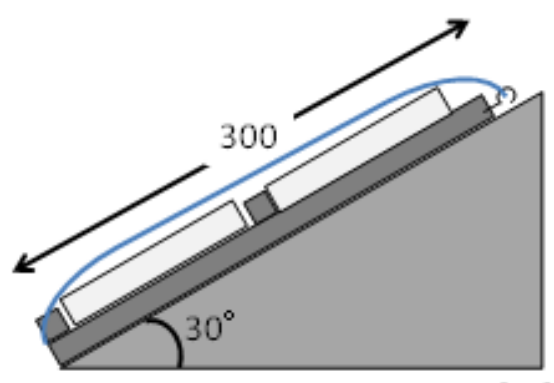

[mIm]

b) Side Elevation of Specimen

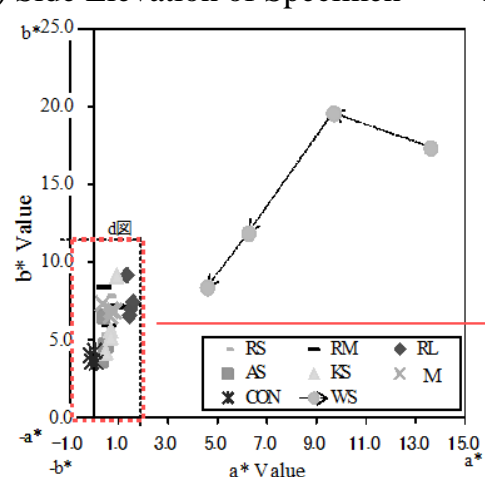

e) Time Changing of $a^{*}$ and $b^{*}$ Value

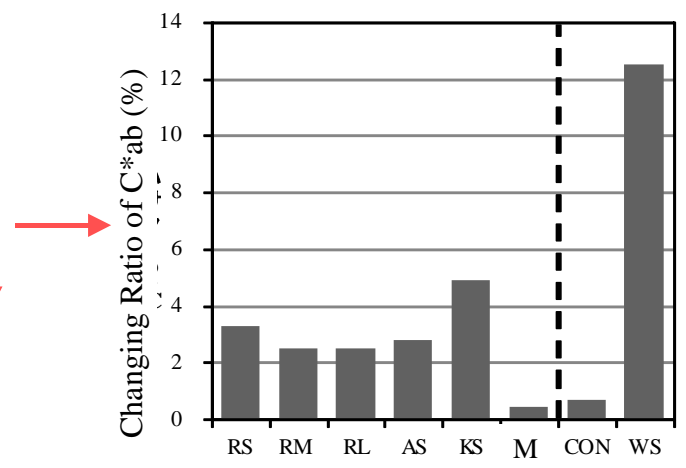

Figure 5. Deterioration on Surface Texture of CCP in a Outer Exposure Condition

The almost CCP series were slowly degrading the surface texture of $\mathrm{L}^{*}$ value, although CCP(RL) was a little earlier degrading by dint of deteriorating a part of wood-chips in board. On the other hands, the WS series of wood was much earlier degrading and the surface of texture became dark color as shown at figure d) and e). 
The similar tendency was occurring at the $\mathrm{C}^{*} \mathrm{ab}$ value as shown at figure $\mathrm{f}$ ), and as one of the conclusive results, the larger amount of areas of wood-chips in CCP, the faster deterioration of surface texture regarding color properties of brightness and color phase.

\section{Use-stage Environmental Effects on Thermal Radiated Effects of Cementious wood-chips}

Compound Products (CCP). Thermal radiated effects on Surface Texture of CCP in a outer exposure condition is indicated in figure 6 .

The 8 kinds of panels had been exposed under the radiating environment among 60 minutes by infrared ray ramp, and measured the 6 points temperature changing conditions at the top and the back sides in each panel specimens. During the measuring temperature changing, 2 times of water wetting to be considered the average amount of raining at $3 \mathrm{~mm} /$ minute in Japan were conducted as shown at figure a).

The comparison with thermal radiated effects during 60 minutes between CCP(RL),M and CON as example is indicated in figure $b$ ). The temperature of standard specimen of CON series was gradually given high temperature from the top side to the back side by radiating infrared ray, and on the other hands the increasing temperature of $\mathrm{CCP}(\mathrm{RL})$ was a little slowly to the back side by dint of absorbing water wetting effectiveness. In additions, the M series of wood-chips masonry unit was much smaller the thermal radiated effects by composing much void volumes and the low heat conduction of wood-chips.
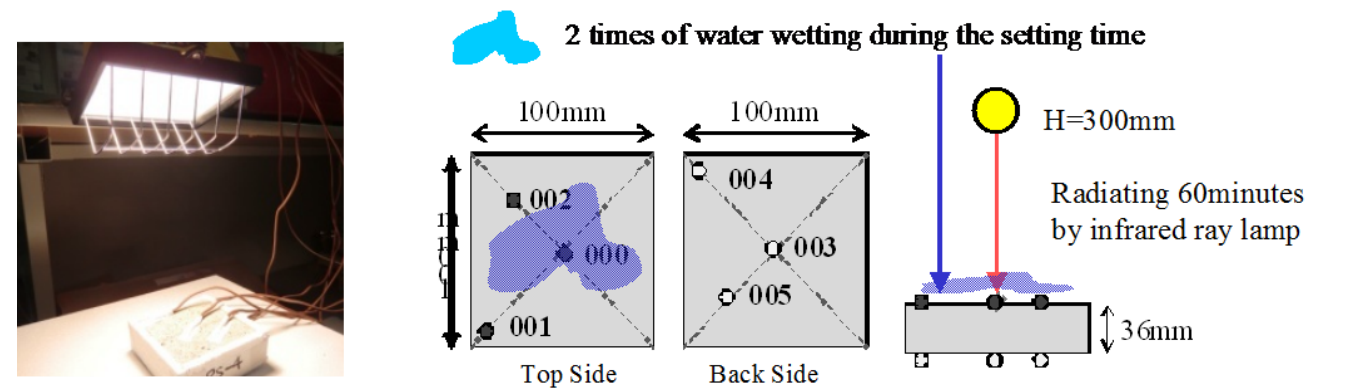

a) Image of Thermal Radiated Test
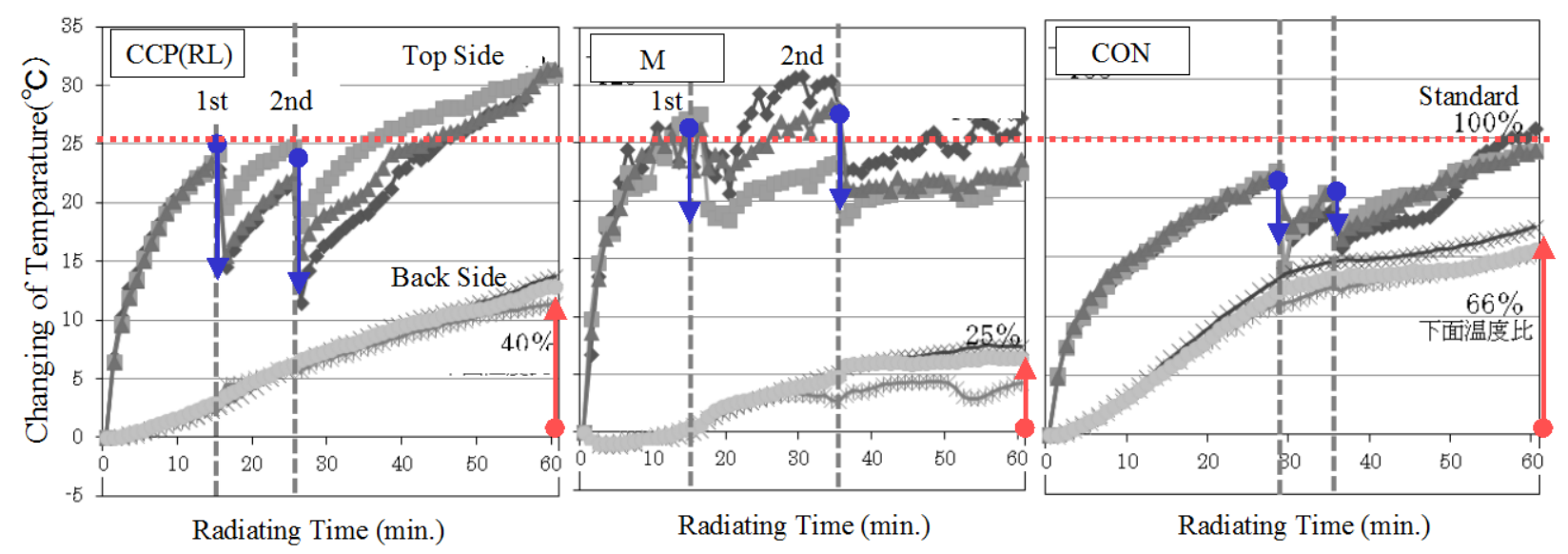

b) Comparison with Changing of Therml Radiated Effects between CCP(RL),M and CON 


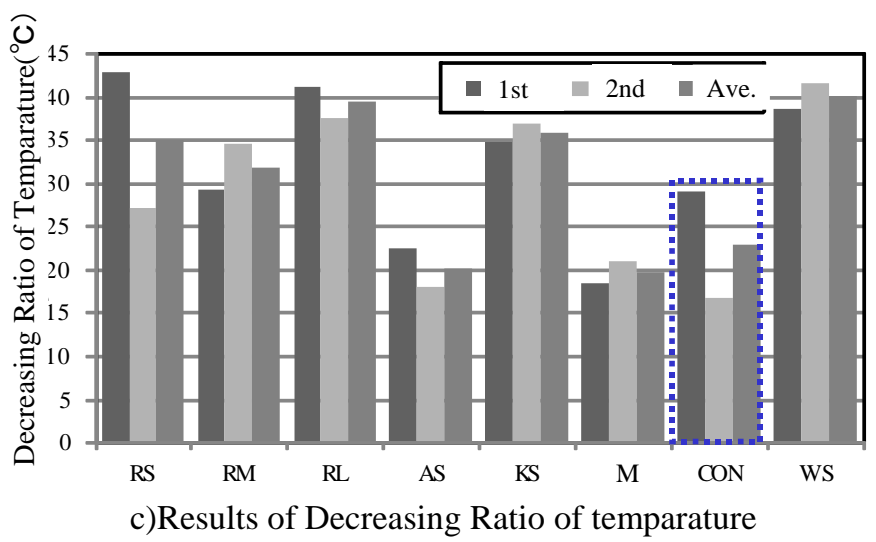

Figure 5. Thermal Radiated Effects of CCP

\section{CONCLUSION}

The following general conclusions can be drawn from the study provided in the paper:

- This study focused on the development of Cementious wood-chips Compound Products (CCP) and the original wood-chips materials of CCP were using disaster waste wood materials released by the Great East Japan Earthquake 2011

- The fundamental properties of CCP was related between the particle sizes of wood-chips, water cement ratio and environmental conditions, and it is expected to be improved the potential performances by optimizing these mixture proportions.

- The use-stage environmental effects on deterioration of surface texture of CCP were given a large effects by the amount of wood-chips and the size, and the thermal radiated conditions was expected to be improved in the case.

\section{ACKNOWLEDGEMENT}

This study was conducted as part of Grant-in-Aid for Basic research B (Yamamoto Hirokazu) of MOE and UDM Project of Kogakuin University . The authors express their gratitude to their financial support.

\section{REFERENCES}

Kasai.Y and others, Production Process and Bending/Compressive Strength of Wood-Chip Concrete with demolished-timber, Transaction of AIJ, No.473, pp1-10(1995) (in Japanese)

Sarja A, Structural Wood-Fiber Concrete, Concrete International, pp.45-49(1989)

Recommendations for Environmentally conscious Practice of Reinforced Concrete Buildings, Architectural institute of Japan (2008)

ISO13315, Environment Management of Concrete and Concrete Structures, Part 1 General Principle(2012) 